Research Article

\title{
Simultaneous Determination of Three Bioactive Constituents from Bletilla striata by UPLC-MS/MS and Application of the Technique to Pharmacokinetic Analyses
}

\author{
Hao Chen $\mathbb{D}^{1},{ }^{1,2}$ Lin Zheng, ${ }^{1}$ Chao-Ye Mei, ${ }^{2}$ Zi-Peng Gong $\mathbb{D}^{1},{ }^{1}$ Yong-Jun Li $\mathbb{D}^{\mathbb{D}},{ }^{3}$ Si-Ying Chen, ${ }^{1}$ \\ Yan-Yu Lan, ${ }^{3}$ Yong-Lin Wang, ${ }^{1}$ Ai-Min Wang, ${ }^{3}$ Yue-Ting Li, ${ }^{1}$ and Yong Huang $\mathbb{D}^{1}$ \\ ${ }^{1}$ State Key Laboratory of Functions and Applications of Medicinal Plants, Guizhou Provincial Key Laboratory of Pharmaceutics, \\ Guizhou Medical University, Guiyang 550004, China \\ ${ }^{2}$ School of Pharmacy, Guizhou Medical University, Guiyang 550004, China \\ ${ }^{3}$ Guizhou Provincial Engineering Research Center for the Development and Application of Ethnic Medicine and TCM, \\ Guizhou Medical University, Guiyang 550004, China
}

Correspondence should be addressed to Yong Huang; mailofhy@126.com

Received 31 May 2019; Revised 11 September 2019; Accepted 27 September 2019; Published 21 October 2019

Academic Editor: Juntra Karbwang

Copyright (C 2019 Hao Chen et al. This is an open access article distributed under the Creative Commons Attribution License, which permits unrestricted use, distribution, and reproduction in any medium, provided the original work is properly cited.

\begin{abstract}
Bletilla striata has been widely used as a valuable hemostatic agent for thousands of years due to the high levels of bioactive constituents it contains. Here, we used a sensitive ultrahigh-performance liquid chromatography-tandem mass spectroscopy (UPLC-MS/MS) method for the simultaneous determination of three major active ingredients of the B. striata extract, namely, $\alpha$-isobutylmalic acid, gymnoside I, and militarine in rat plasma. The three major active ingredients were determined using the multiple reaction monitoring $(\mathrm{MRM})$ mode at $\mathrm{m} / \mathrm{z} 189 \longrightarrow 129$ for $\alpha$-isobutylmalic acid, $\mathrm{m} / \mathrm{z} 457.2 \longrightarrow 285.1$ for gymnoside I, $\mathrm{m} / \mathrm{z}$ $725.3 \longrightarrow 457.2$ for militarine, and $\mathrm{m} / \mathrm{z} 417.0 \longrightarrow 267.0$ for the IS puerarin. All calibration curves showed good linearity $\left(R^{2} \geq 0.999\right)$ over the concentration range with the lower limit of quantification between 0.015 and $0.029 \mu \mathrm{g} / \mathrm{mL}$. The relative standard deviations of intraday and interday measurements were less than $15 \%$, and the method was accurate within $93.3-100.4 \%$. The extraction recovery was $92.65-100.98 \%$, and no matrix effect was observed. The results indicated that after oral administration of $B$. striata in rats, the $T_{\max }$ of $\alpha$-isobutylmalic acid was significantly longer than that of gymnoside I and militarine and the mean residence time and area under the curve of $\alpha$-isobutylmalic acid and gymnoside I in rats were significantly higher than those of militarine. Moreover, the blood concentration-time curve of $\alpha$-isobutylmalic acid showed double peaks, suggesting that $\alpha$-isobutylmalic acid could exhibit the phenomenon of enterohepatic circulation or metabolic conversion. We also explored some of the pharmacokinetic characteristics of three ingredients from B. striata extract in vivo, and the data obtained may provide a basis for the further investigation of B. striata.
\end{abstract}

\section{Introduction}

Bletilla striata (Thunb.) Reichb. f. (Orchidaceae) is a medicinal plant, the dry tubers of which have a hemostatic effect and are prescribed by the Chinese Pharmacopoeia as a medicinal part [1]. It is widely used in traditional Chinese herbal medicines for thousands of years in China and first recorded in Shennong's Materia Medica [2]. It is bitter, sweet, and puckery in flavor and slightly cool and astringent in nature, and it acts on the lung, liver, and stomach meridians $[1,2]$. The dried tubers of $B$. striata can effectively inhibit leakage of blood and stop bleeding, disperse swelling, and promote tissue regeneration [3]. Thus, it has been used as a valuable hemostatic agent for the treatment of hemoptysis, vomiting blood, traumatic bleeding, and ulcerative carbuncles $[4,5]$. Furthermore, it is not only used in the treatment of sores, chapped skin, and swelling $[6,7]$ but also has antibacterial $[8,9]$ and antitumor effects [10-12]. After years of research, more than 90 compounds have been isolated from B. striata tubers, including benzyl compounds, 
phenanthrene, glycosides, anthocyanins, triterpenes, and steroids [10, 13-15]. Moreover, our previous pharmacological work has confirmed that B. striata extract shows a hemostatic effect by promoting platelet aggregation $[16,17]$.

However, most of these reports only focus on the pharmacological effects and chemical composition of $B$. striata extract, and pharmacokinetic studies on B. striata extract have not been reported. Adequate pharmacokinetic data for traditional medicines are critical to ensure safe and proper application. To study the pharmacokinetic properties, the primary active ingredients are typically selected to characterize the pharmacokinetic profile of these drugs. The study will provide a method to explore the pharmacokinetic characteristics of the main representative components of $B$. striata clinical applications. According to serum medicinal chemistry, the pharmacological activity of bioactive ingredients depends largely on whether they are absorbed into the blood and maintain a certain blood concentration [18]. In our previous study, we found that $\alpha$-isobutylmalic acid, gymnoside I, and militarine are relatively high in $B$. striata extract [19], and after oral B. striata extract in rats, three components were detected in the serum [20]. Recent research has shown that militarine can not only be metabolized to $\alpha$-isobutylmalic acid and gymnoside I in zebrafish but also that it is the most abundant active component in $B$. striata [21-23]. Furthermore, militarine can improve intelligence, learning ability, and memory and can also prevent senile dementia and plays a protective role against agingrelated neural defects $[24,25]$. At the same time, studies have shown that $\alpha$-isobutylmalic acid and gymnoside I may be potential pharmacological components [26, 27]. Therefore, we selected $\alpha$-isobutylmalic acid, gymnoside I, and militarine as indicative active components of $B$. striata extract to study the pharmacokinetics and absolute bioavailability of these three compounds in rats.

Here, we report the development and validation of a novel, sensitive, and selective UPLC-MS/MS method for the simultaneous determination of $\alpha$-isobutylmalic acid, gymnoside I, and militarine concentrations and its application to investigate their pharmacokinetics and absolute bioavailability in the rat's plasma after intravenous injection and oral administration of $B$. striata extract.

\section{Materials and Methods}

2.1. Materials and Reagents. The standards of puerarin (purity: 95.4\%) were obtained from the National Institutes for Food and Drug Control (Beijing, China). $\alpha$-Isobutylmalic acid, gymnoside I (purity $\geq 95 \%$ ), and militarine (purity $\geq 98 \%$ ) were isolated from B. striata in our laboratory. The structure and purity of these compounds were confirmed using IR, ${ }^{1} \mathrm{H}$ nuclear magnetic resonance (NMR), MS, and HPLC-UV. The structures of the three components and puerarin are shown in Figure 1. HPLC-grade acetonitrile and methanol were purchased from Merck Co. (Darmstadt, Germany). HPLC-grade formic acid was supplied by Dikma (Richmond Hill, NY, USA). Distilled water was obtained from Watsons Group Co. Ltd. (Hong Kong, PR China). All other chemicals were of analytical grade.
The extraction of $B$. striata was conducted using a method described by Zhao et al. [16]. The dried medicinal $B$. striata $(10 \mathrm{~kg})$ was powdered and extracted 3 times $(2 \mathrm{~h}$ each time) with $95 \%$ ethanol $(1: 4 \mathrm{~m} / \mathrm{v})$. The decoction was combined and concentrated under reduced pressure to $10 \mathrm{~L}$. The residue was directly subjected to D101 macroporous resin eluted with $80 \%$ aqueous ethanol. The elution liquid was finally concentrated under reduced pressure, and the concentrates were dried to powder by microwave vacuum. The $\alpha$-isobutylmalic acid, gymnoside I, and militarine contents of the B. striata extracts were determined under the same chromatography conditions as described in the following sections and found to be $2.36 \%, 1.07 \%$, and $26.37 \%$, respectively.

2.2. Animals. Sprague-Dawley rats (weighing $230 \pm 20 \mathrm{~g}$ ) were provided by Chongqing Tengxin Biotechnology Co., Ltd. (Chongqing, China, certificate No. SCXK (Yu) 20150001). All studies were approved by the Animal Ethics Committee at Guizhou Medical University and conducted in accordance with the guidelines of the Committee on the Care and Use of Laboratory Animals in China.

\subsection{Instrumentation and Analytical Conditions of UPLC-MS/} MS. An ACQUITY ${ }^{\mathrm{TM}}$ UPLC system (Waters Corp., Milford, MA, USA) with a conditioned autosampler and the ACQUITY $^{\text {тм }}$ UPLC BEH $\mathrm{C}_{18}$ analytical column $(50 \mathrm{~mm} \times 2.1 \mathrm{~mm}$, internal diameter, $1.7 \mu \mathrm{m}$; Waters Corp., Milford, MA, USA) were used, to which a $6 \mathrm{~mm}$ precolumn filter unit was added. Analysis was carried out with an elution gradient of (A) acetonitrile and (B) water (both containing $0.1 \%$ formic acid) at a flow rate of $0.35 \mathrm{~mL} / \mathrm{min}$ as follows: $0-0.5 \min (10 \% \mathrm{~A}), 0.5-1.0 \mathrm{~min}(10-30 \% \mathrm{~A}), 1.0-$ $2.0 \mathrm{~min}(30-35 \% \mathrm{~A}), 2.0-3.0 \mathrm{~min}(35-38 \% \mathrm{~A}), 3.0-4.0 \mathrm{~min}$ $(38-90 \% \mathrm{~A})$, and $4.0-5.0 \mathrm{~min}(90-10 \% \mathrm{~A})$. The column and autosampler were maintained at $45^{\circ} \mathrm{C}$ and $15^{\circ} \mathrm{C}$, respectively. The injection volume was $2 \mu \mathrm{L}$.

Mass spectrometric detection was performed using a Waters ACQUITY ${ }^{\mathrm{TM}}$ TQD triple quadrupole tandem mass spectrometer (Waters Corp., Manchester, UK) with an ESI interface in the positive ionization mode. The MS conditions were as follows: capillary voltage, $3.0 \mathrm{kV}$; desolvation gas flow, $650 \mathrm{~L} / \mathrm{h}$ of nitrogen; and cone gas flow, $50 \mathrm{~L} / \mathrm{h}$ of nitrogen. The collision gas (Ar) flow for MS/MS was maintained at $0.16 \mathrm{~mL} / \mathrm{min}$ for collision-induced dissociation (CID). The source and desolvation gas temperatures were $120^{\circ} \mathrm{C}$ and $350^{\circ} \mathrm{C}$, respectively. The multiple reaction monitoring (MRM) mode was used for quantification. The optimal MRM mode parameters of the analytes and internal standard (IS) are given in Table 1. All data were acquired using Masslyn $\mathrm{x}^{\mathrm{TM}} \mathrm{V}$ 4.1 Software and processed using Quanlyna $^{\text {TM }}$ V4.1 (Waters Corp., Millford, MA, USA).

2.4. Standard Solution, Calibration Standards, and Quality Control (QC) Samples. Stock solutions of puerarin (IS), $\alpha$-isobutylmalic acid, gymnoside I, and militarine were prepared by dissolving the appropriate amounts of each 
<smiles>CC(C)C[C@@](O)(CC(=O)OCc1ccc(O[C@@H]2O[C@H](CO)[C@@H](O)[C@H](O)[C@H]2O)cc1)C(=O)OCc1ccc(O[C@@H]2O[C@H](CO)[C@@H](O)[C@H](O)[C@H]2O)cc1</smiles><smiles>CC(C)C[C@](O)(CC(=O)O)C(=O)OCc1ccc(O[C@@H]2O[C@H](CO)[C@@H](O)[C@H](O)[C@H]2O)cc1</smiles><smiles>CC(C)C[C@](O)(CC(=O)O)C(=O)O</smiles><smiles>O=c1c(-c2ccc(O)cc2)coc2c([C@@H]3O[C@H](CO)[C@@H](O)[C@H](O)[C@H]3O)c(O)ccc12</smiles>

Puerarin

FIgURe 1: Chemical structures of $\alpha$-isobutylmalic acid, gymnoside I militarine, and puerarin (internal standard).

TABle 1: Precursor/product ion pairs and parameters for MRM of the analytes and the internal standard (IS) puerarin.

\begin{tabular}{lccc}
\hline Component & Transition $(m / z)$ & Cone voltage $(\mathrm{V})$ & Collision energy $(\mathrm{eV})$ \\
\hline$\alpha$-Isobutylmalic acid & $189 \longrightarrow 129$ & 30 & 15 \\
Gymnoside I & $457.2 \longrightarrow 285.1$ & 35 & 15 \\
Militarine & $725.3 \longrightarrow 457.2$ & 40 & 20 \\
Puerarin (IS) & $417.0 \longrightarrow 267.0$ & 40 & 30 \\
\hline
\end{tabular}

standard substance in $10 \mathrm{~mL}$ of methanol to yield concentrations of $2.90 \mathrm{mg} / \mathrm{mL}, 1.50 \mathrm{mg} / \mathrm{mL}, 1.10 \mathrm{mg} / \mathrm{mL}$, and $0.405 \mathrm{mg} / \mathrm{mL}$, respectively. Working solutions for calibration were prepared at concentrations of $0.015,0.029$, $0.145,0.454,1.362,4.086,12.259,36.778$, and $110.333 \mu \mathrm{g} /$ $\mathrm{mL}$ for $\alpha$-isobutylmalic acid, $0.011,0.022,0.11,0.55,2.75$, 13.75 , and $27.50 \mu \mathrm{g} / \mathrm{mL}$ for gymnoside $\mathrm{I}$, and $0.015,0.098$, $2.642,7.926,23.778$, and $99.333 \mu \mathrm{g} / \mathrm{mL}$ for militarine. Quality control (QC) samples were prepared, containing $\alpha$-isobutylmalic acid $(0.029,4.09$, and $36.78 \mu \mathrm{g} / \mathrm{mL})$, gymnoside I $(0.02,2.75$, and $13.75 \mu \mathrm{g} / \mathrm{mL})$, militarine $(0.015,2.64$, and $23.78 \mu \mathrm{g} / \mathrm{mL})$, and gymnoside I $(0.6,19.2$, and $57.6 \mu \mathrm{g} / \mathrm{mL}$ ) using the same method as for the calibration samples. All the stocks and working solutions were stored at $4^{\circ} \mathrm{C}$ and brought to room temperature before use.
2.5. Sample Preparation. Ten microliters of the IS solution (puerarin, $10 \mu \mathrm{g} / \mathrm{mL}$ in methanol) and $50 \mu \mathrm{L}$ of $1 \%$ formic acid were added to $100 \mu \mathrm{L}$ of rat plasma. Proteins were precipitated by addition of $400 \mu \mathrm{L}$ of methanol, vortexing for $1 \mathrm{~min}$, sonication for $5 \mathrm{~min}$, followed by centrifugation at $13225 \times \mathrm{g}$ for $10 \mathrm{~min}$ at $4^{\circ} \mathrm{C}$, collecting the supernatant in a centrifuge tube, and drying at $37^{\circ} \mathrm{C} \mathrm{N}_{2}$. Subsequently, $300 \mu \mathrm{L}$ of the initial mobile phase was dissolved, sonicated for $5 \mathrm{~min}$, and centrifuged at $5^{\circ} \mathrm{C}$ and $13225 \times g$ for $5 \mathrm{~min}$, and the supernatant was used for analysis by UPLC-MS/MS.

2.6. Method Validation. Method validation for the quantification of these $B$. striata compounds in rat plasma was performed by following the US Food and Drug Administration Bio-analytical Method Validation Guide with the 
following parameters evaluated: selectivity specificity, matrix effect, linearity, accuracy, precision, recovery, and stability.

2.6.1. Specificity and Selectivity. Specificity and selectivity of the method were evaluated by analyzing blank rat plasma, blank rat plasma spiked with $\alpha$-isobutylmalic acid, gymnoside I, militarine, and IS, and rat plasma collected at $0.5 \mathrm{~h}$ after oral and intravenous administration of B. striata extract spiked with IS.

2.6.2. Linearity and Lower Limit of Quantification. To investigate linearity and lower limit of quantification (LLOQ), the stock solution of each analyte was diluted with methanol to make a series of working solutions. The calibration samples of each analyte were prepared independently by adding a series of different concentrations of working solution $(50 \mu \mathrm{L})$, IS solution $(10 \mu \mathrm{L}, 10 \mu \mathrm{g} / \mathrm{mL})$, formic acid $(50 \mu \mathrm{L}, 1 \%)$, and $400 \mu \mathrm{L}$ methanol to blank rat plasma $(100 \mu \mathrm{L})$ to determine linearity and LLOQ. The LLOQ was defined as the lowest concentration on the calibration curve that could fulfill the analytical requirement of $\mathrm{S} / \mathrm{N} \geq 10$ with an acceptable accuracy and precision (within $\pm 20 \%$ ).

2.6.3. Precision and Accuracy. Precision was evaluated using relative standard deviation (RSD), and accuracy was determined via analytical recovery. The accuracy and the precision of the assay for intraday and interday determinations were evaluated by the analysis of three QC samples $(n=5)$ on the same day and on three consecutive validation days.

2.6.4. Extraction Recovery and Matrix Effect. The extraction recoveries of three analytes were determined by comparing the peak areas of the low-, middle-, and high-QC samples prespiked in blank plasma with those postspiked in blank plasma $(n=5)$. The matrix effect was determined by comparing the peak areas of the QC samples prespiked in blank plasma with those in the initial mobile phase $(n=5)$.

2.6.5. Stability. The stability of each compound in rat plasma was evaluated using mixtures containing low, medium, or high concentrations of the QC sample $(n=5$ for each concentration level). The stability of each compound was tested under three conditions: room temperature for $6 \mathrm{~h}$, three freeze $\left(-20^{\circ} \mathrm{C}\right)$-thaw (room temperature) cycles, and storage at $4^{\circ} \mathrm{C}$ for $12 \mathrm{~h}$.

2.7. Pharmacokinetic Study. The twelve Sprague-Dawley rats were housed under a controlled temperature regimen $\left(22 \pm 1^{\circ} \mathrm{C}\right)$ and relative humidity of $50-70 \%$. The animals were maintained on a $12 \mathrm{~h}$ light/12 h dark cycle and had free access to food and water. They were fasted for $12 \mathrm{~h}$ before each experiment but allowed to drink freely during this time. Before the experiment, the B. striata extracts' intravenous and oral dosing solutions were prepared in physiological saline at concentrations of $1.03 \mathrm{~g} / \mathrm{mL}$ and $2.78 \mathrm{~g} / \mathrm{mL}$, respectively. The 12 rats were randomly divided into two groups with 6 rats in each group. Group 1 underwent oral administration $(22.2 \mathrm{~g} / \mathrm{kg})$, and group 2 underwent intravenous administration $(1.64 \mathrm{~g} / \mathrm{kg})$. Blood samples $(0.3 \mathrm{~mL})$ were collected from the external right jugular veins of the rats into heparinized tubes at the designated time points $(0.033,0.083,0.167,0.33,0.5,1$, $1.5,2,10,24,36$, and $48 \mathrm{~h}$ for group 1 and $0.033,0.083$, $0.167,0.25,0.33,0.5,0.75,1,1.6$, and $2 \mathrm{~h}$ for group 2$)$. The blood samples were immediately centrifuged at $3000 \times \mathrm{g}$ for $5 \mathrm{~min}$. The plasma was removed and frozen at $-20^{\circ} \mathrm{C}$ until further analysis.

2.8. Statistical Analysis. Data are represented as mean\pm standard deviation. To determine the pharmacokinetic parameters, the concentration-time data were analyzed by DAS 2.0 software (Mathematical Pharmacology Professional Committee of China, Shanghai, China). Statistical analysis was performed using the statistical software package Statistical Product and Service Solutions (SPSS 11.5, USA). The absolute bioavailability was calculated using the following equation: $\mathrm{F}(\%)=[\mathrm{AUC0}-t($ oral $) \times$ dose (i.v.) $] /[$ AUC0 $-t$ (i.v.) $\times$ dose $($ oral $)]) \times 100$.

\section{Results and Discussion}

\subsection{Method Validation}

3.1.1. Specificity and Selectivity. The specificity of the method was determined by comparing the chromatograms of blank (unspiked) plasma with the corresponding spiked plasma. Typical chromatograms of blank plasma (A), spiked plasma (B), and plasma from a pharmacokinetic study (C) are shown in Figure 2. The retention times for $\alpha$-isobutylmalic acid, gymnoside I, militarine, and puerarin (IS) were $1.54,1.70,1.81$, and $1.30 \mathrm{~min}$, respectively. There was no endogenous interference in the MRM mode for any of the analytes.

\subsubsection{Linearity and Lower Limit of Quantification.} Typical equations for calibration curves and LLOQ of the three analytes are shown in Table 2. All the three analytes exhibited good linearity with correlation coefficients within the range of $0.9991-0.9994$.

3.1.3. Precision and Accuracy. As shown in Table 3, the results for intraday and interday precision and accuracy for the three compounds indicated that the intraday and interday RSDs were all less than $10.4 \%$ and $5.0 \%$, respectively, while the corresponding accuracy ranged from $93.3 \%$ to $100.4 \%$. These data suggest that both precision and accuracy achieved with this method are acceptable.

3.1.4. Extraction Recovery and Matrix Effect. The matrix effects can be regarded; all ratios $(\mathrm{A} / \mathrm{B} \times 100) \%$ were 

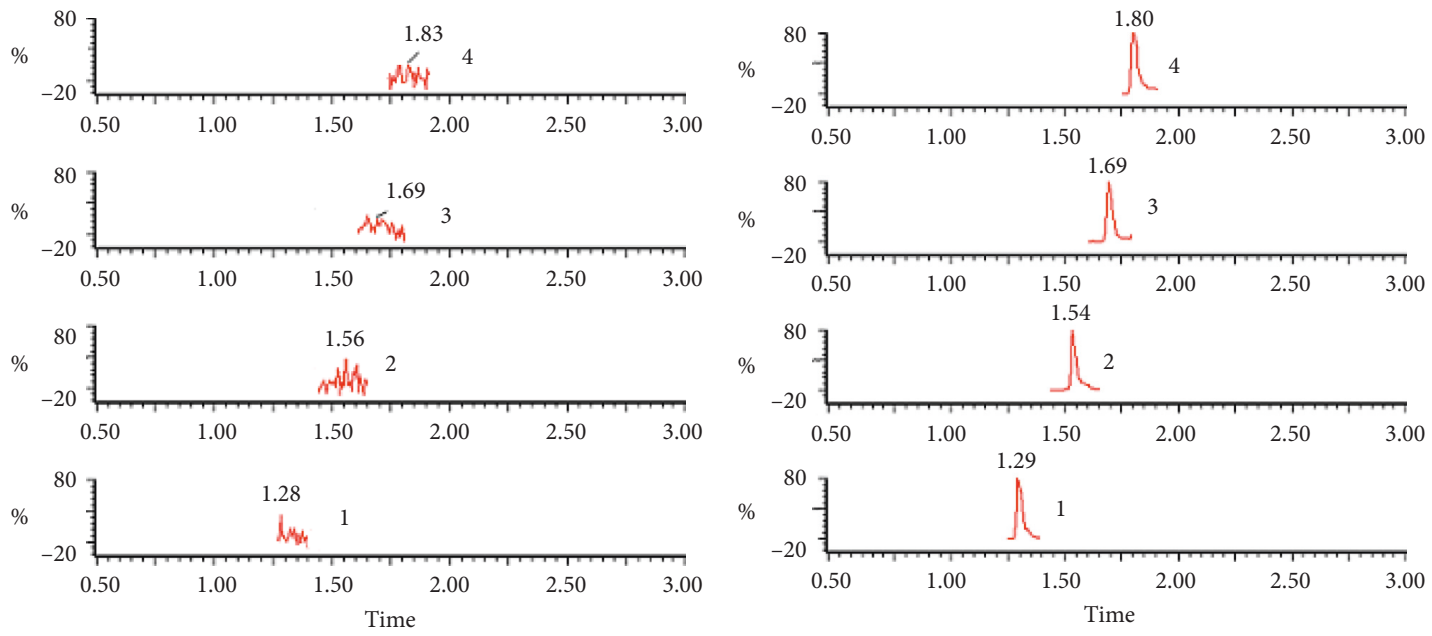

(a)

(b)
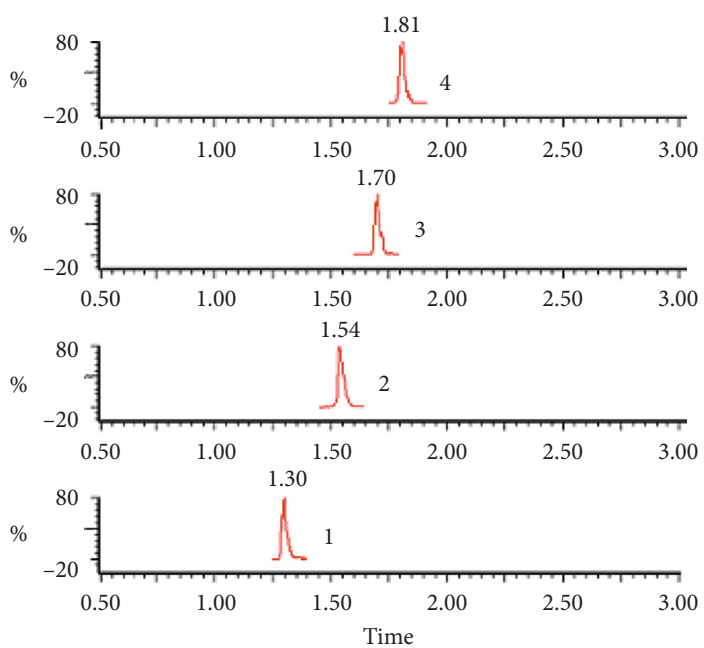

(c)

FIGURE 2: Chromatograms of the three analytes and (internal standard, IS) in rat plasma. Blank plasma sample (a); blank rat plasma sample spiked with three analytes ( $\alpha$-isobutylmalic acid, gymnoside I and militarine) and IS (quercetin) (b); rat plasma sample obtained $0.5 \mathrm{~h}$ after oral administration and intravenous administration of B. striata extract (c). (1) Puerarin (IS), (2) $\alpha$-isobutylmalic acid, (3) gymnoside I, (4) militarine.

TABLE 2: Typical equations for calibration curves and lower limit of quantification (LLOQ) $(n=3)$.

\begin{tabular}{lcccc}
\hline Analytes & Calibration curves & Linear range $(\mu \mathrm{g} / \mathrm{mL})$ & $R^{2}$ & LLOQ $(\mu \mathrm{g} / \mathrm{mL})$ \\
\hline$\alpha$-Isobutylmalic acid & $Y=0.3148 X+0.0072$ & $0.029 \sim 110.33$ & 0.9992 & 0.029 \\
Gymnoside I & $Y=0.333 X-0.0002$ & $0.022 \sim 27.50$ & 0.9994 & 0.022 \\
Militarine & $Y=0.2126 X-0.0001$ & $0.015 \sim 99.33$ & 0.9991 & 0.015 \\
\hline
\end{tabular}

between $93.21 \%$ and $101.74 \%$, showing that there was no significant interference from endogenous substances. The extraction recoveries were in the range $92.65 \%$ to $100.98 \%$. These results showed that all values were within the acceptable ranges (Table 4).

3.1.5. Stability. The three analytes were stable under all testing conditions, including room temperature for $6 \mathrm{~h}$, three freeze $\left(-20^{\circ} \mathrm{C}\right)$-thaw (room temperature) cycles, and storage at $4^{\circ} \mathrm{C}$ for $12 \mathrm{~h}$. The results for all conditions are summarized in Table 5 .
3.2. Pharmacokinetics. The developed and validated UPLCMS/MS method was successfully applied for the determination of $\alpha$-isobutylmalic acid, gymnoside I, and militarine pharmacokinetics. The drug concentration-time curves after the intravenous injection of $1.64 \mathrm{~g} / \mathrm{kg} \mathrm{B}$. striata extract and oral administration of $22.2 \mathrm{~g} / \mathrm{kg} \mathrm{B}$. striata extract are shown in Figures 3 and 4 . The pharmacokinetic parameters are given in Table 6.

As seen from Figure 3 and Table 6, the peak time $\left(T_{\max }\right)$ of gymnoside $\mathrm{I}$ and militarine were $0.16 \mathrm{~h}$ and $1.44 \mathrm{~h}$, respectively, both less than $1.5 \mathrm{~h}$, but the $T_{\max }$ of $\alpha$-isobutylmalic acid was as long as $6.44 \mathrm{~h}$, significantly 
TABLE 3: Summary of precision and accuracy of quality control samples added to rat plasma $(n=5)$.

\begin{tabular}{|c|c|c|c|c|c|c|c|}
\hline \multirow[b]{2}{*}{ Analytes } & \multirow[b]{2}{*}{$\begin{array}{c}\text { Spiked } \\
\text { concentration }(\mu \mathrm{g} / \\
\mathrm{mL})\end{array}$} & \multicolumn{3}{|c|}{ Intraday } & \multicolumn{3}{|c|}{ Interday } \\
\hline & & $\begin{array}{c}\text { Calculated } \\
\text { concentration }(\mu \mathrm{g} / \\
\mathrm{mL})\end{array}$ & $\begin{array}{c}\text { Precision } \\
\text { (RSD\%) }\end{array}$ & $\begin{array}{c}\text { Accuracy } \\
(\%)\end{array}$ & $\begin{array}{c}\text { Calculated } \\
\text { concentration }(\mathrm{ng} / \\
\mathrm{mL})\end{array}$ & $\begin{array}{c}\text { Precision } \\
(\mathrm{RSD}, \%)\end{array}$ & $\begin{array}{c}\text { Accuracy } \\
(\%)\end{array}$ \\
\hline \multirow{3}{*}{$\begin{array}{l}\alpha \text {-Isobutylmalic } \\
\text { acid }\end{array}$} & 0.029 & $0.029 \pm 0.001$ & 6.5 & 101.3 & $0.028 \pm 0.001$ & 5.34 & 96.6 \\
\hline & 4.09 & $3.84 \pm 0.04$ & 10.4 & 93.9 & $3.83 \pm 0.05$ & 1.3 & 99.7 \\
\hline & 36.78 & $36.29 \pm 1.45$ & 4.0 & 98.7 & $36.11 \pm 1.21$ & 3.4 & 98.2 \\
\hline \multirow{3}{*}{ Gymnoside I } & 0.02 & $0.02 \pm 0.001$ & 4.6 & 100.9 & $0.02 \pm 0.001$ & 5.5 & 100.4 \\
\hline & 2.75 & $2.62 \pm 0.09$ & 3.3 & 95.4 & $2.60 \pm 0.09$ & 3.5 & 94.5 \\
\hline & 13.75 & $13.19 \pm 0.02$ & 1.5 & 95.9 & $13.45 \pm 0.37$ & 2.8 & 97.8 \\
\hline \multirow{3}{*}{ Militarine } & 0.015 & $0.014 \pm 0.002$ & 11.4 & 93.3 & $0.014 \pm 0.001$ & 8.4 & 93.3 \\
\hline & 2.64 & $2.57 \pm 0.05$ & 1.9 & 97.3 & $2.60 \pm 0.06$ & 2.3 & 98.5 \\
\hline & 23.78 & $23.03 \pm 1.34$ & 5.8 & 96.8 & $23.29 \pm 1.13$ & 4.9 & 97.9 \\
\hline
\end{tabular}

TABLe 4: Matrix effects and extraction recoveries of the three compounds $(n=5)$.

\begin{tabular}{|c|c|c|c|c|c|}
\hline \multirow{2}{*}{ Analytes } & \multirow{2}{*}{ Spiked concentration $(\mathrm{ng} / \mathrm{mL})$} & \multicolumn{2}{|c|}{ Extraction recovery } & \multicolumn{2}{|c|}{ Matrix effect } \\
\hline & & Mean \pm SD (\%) & RSD (\%) & Mean \pm SD (\%) & RSD (\%) \\
\hline \multirow{3}{*}{$\alpha$-Isobutylmalic acid } & 0.029 & $99.68 \pm 4.50$ & 4.5 & $93.21 \pm 3.54$ & 3.8 \\
\hline & 4.09 & $95.77 \pm 1.12$ & 1.2 & $96.45 \pm 0.78$ & 0.8 \\
\hline & 36.78 & $100.98 \pm 2.14$ & 2.1 & $100.09 \pm 2.45$ & 2.4 \\
\hline \multirow{3}{*}{ Gymnoside I } & 0.22 & $93.99 \pm 6.47$ & 6.9 & $98.73 \pm 7.59$ & 7.7 \\
\hline & 2.75 & $92.65 \pm 8.09$ & 8.7 & $101.74 \pm 3.34$ & 3.3 \\
\hline & 13.75 & $94.71 \pm 4.03$ & 4.3 & $99.08 \pm 0.67$ & 0.7 \\
\hline \multirow{3}{*}{ Militarine } & 0.015 & $100.16 \pm 8.81$ & 8.8 & $94.81 \pm 1.56$ & 1.6 \\
\hline & 2.64 & $94.78 \pm 2.17$ & 2.3 & $95.63 \pm 2.53$ & 2.6 \\
\hline & 23.78 & $99.66 \pm 5.36$ & 5.4 & $99.91 \pm 6.36$ & 6.4 \\
\hline
\end{tabular}

longer than the $T_{\max }$ of gymnoside I and militarine. It was shown that the absorption rate of militarine and gymnoside I was faster than that of $\alpha$-isobutylmalic acid in vivo. Comparing the mean residence time (MRT) of the three components in the rats, it can be found that the MRT of the three components after intravenous administration was not much different, but the MRT of the three components after oral administration was longer than that after intravenous administration. The results showed that the prolongation of MRT after oral administration mainly came from the influence of gastrointestinal absorption during oral administration, but the extent of MRT prolongation may be due to the transformation relationship between the three components. Related studies have shown that militarine can be rapidly converted into $\alpha$-isobutylmalic acid and gymnoside I in vivo [27]. Due to the structural relationship between the three components [21], militarine can be transformed into gymnoside I and $\alpha$-isobutylmalic acid by the action of the gastrointestinal tract in vivo. Eventually, the MRT of the three components after oral administration was extended to varying degrees.

At the same time, a double-peak phenomenon was noticed for $\alpha$-isobutylmalic acid (Figure 3 ). We speculate two possible causes for the same. First, $\alpha$-isobutylmalic acid had an intestinal hepatic circulation in the gastrointestinal tract. Second, due to the metabolic conversion of militarine into $\alpha$-isobutylmalic acid in vivo, the continuous supplementation of $\alpha$-isobutylmalic acid in the body led to an increase in the concentration of $\alpha$-isobutylmalic acid in blood, resulting in the bimodal phenomenon.

Although the concentration of militarine in B. striata extract was as high as $26.37 \%$, the "absolute bioavailability" of militarine in rats after oral absorption was $0.6 \%$, while $\alpha$-isobutylmalic acid and gymnoside I had better absolute bioavailability in vivo, $87.45 \%$ and $9.8 \%$, respectively. However, the composition of the extract of traditional Chinese medicine is complicated, and there may be a conversion among the components. The purpose of the concept is to measure the extent of absorption and transformation of militarine, $\alpha$-isobutylmalic acid, and gymnoside I. We observed that militarine had a lower "bioavailability," indicating that militarine may undergo extensive metabolism in vivo. At the same time, due to the structural relationship among militarine, gymnoside I, and $\alpha$-isobutylmalic acid, not only militarine can be converted to $\alpha$-isobutylmalic acid, but also gymnoside I may be converted to $\alpha$-isobutylmalic acid. This indicates that the higher "bioavailability" of $\alpha$-isobutylmalic acid may be due to the conversion of militarine, gymnoside I, and other undetected components so that $\alpha$-isobutylmalic acid has a higher blood concentration in vivo. At the same time, the MRT and the area under the curve (AUC) of $\alpha$-isobutylmalic acid and gymnoside $\mathrm{I}$ in rats were significantly greater than that of militarine, indicating that the process of therapeutic action of B. striata in vivo was likely due to the metabolic conversion of militarine to 


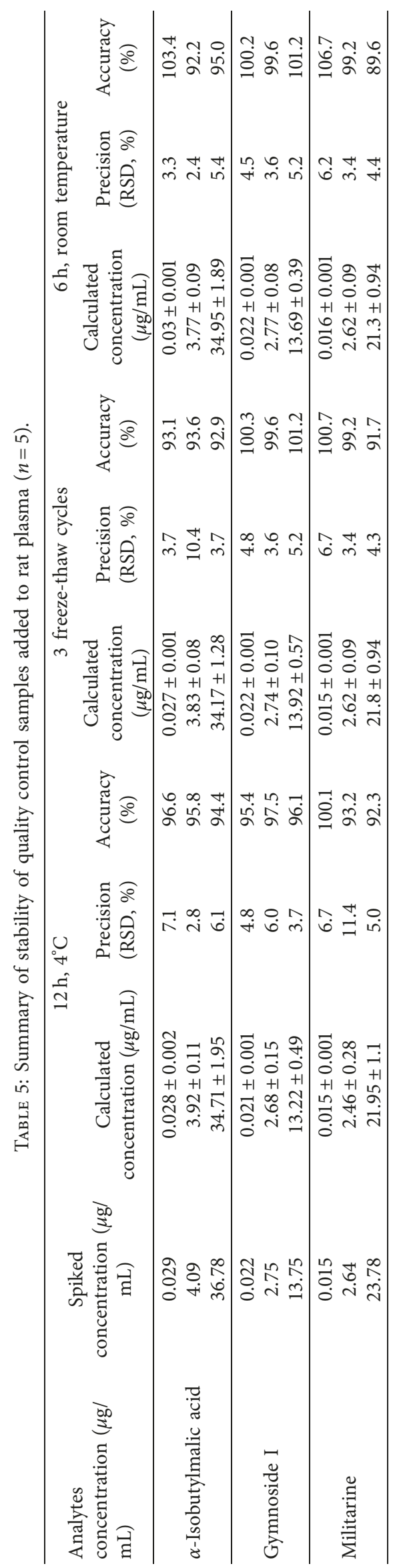




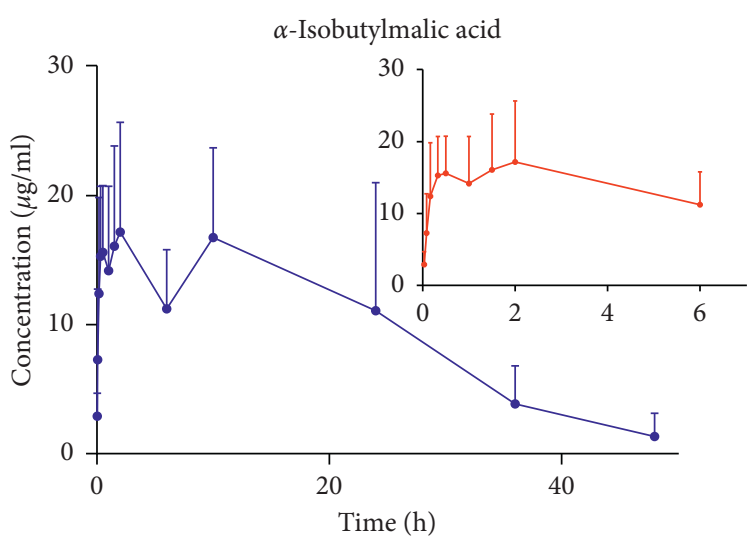

(a)

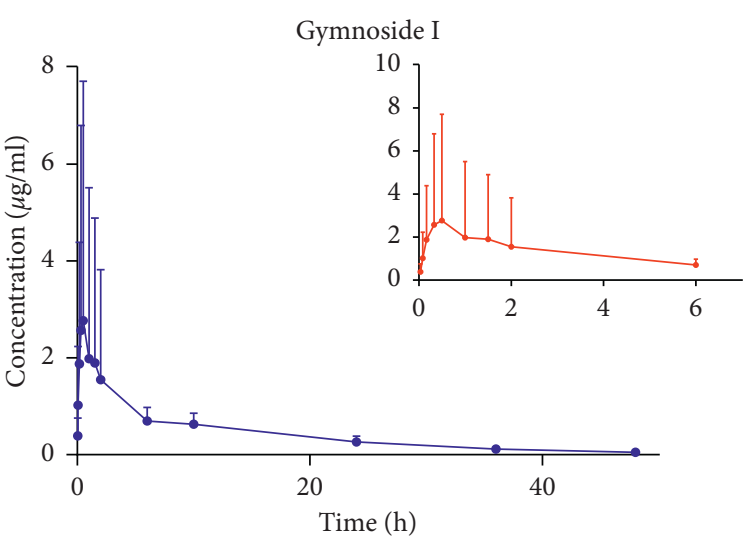

(b)

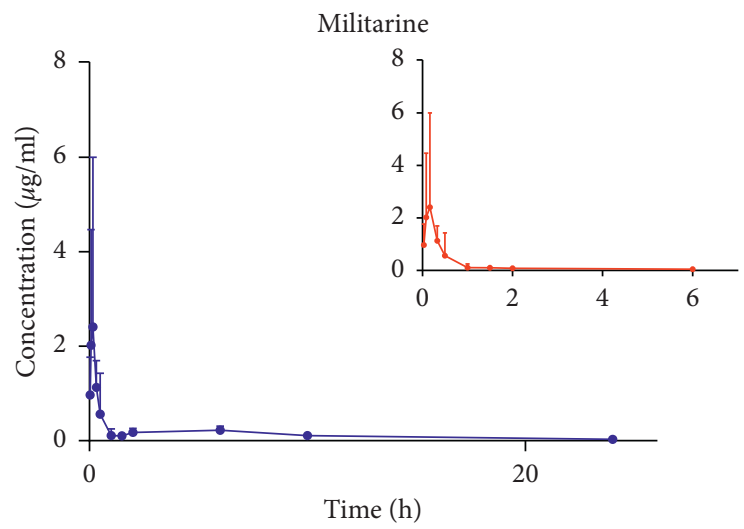

(c)

FIgURE 3: Mean plasma concentration-time curves of $\alpha$-isobutylmalic acid, gymnoside I, and militarine after oral administration of $B$. striata extract to rats $(n=6)$.

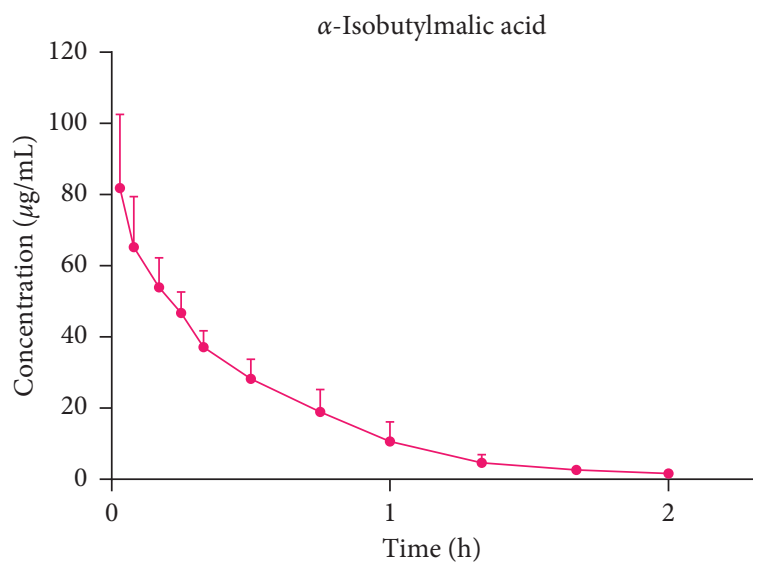

(a)

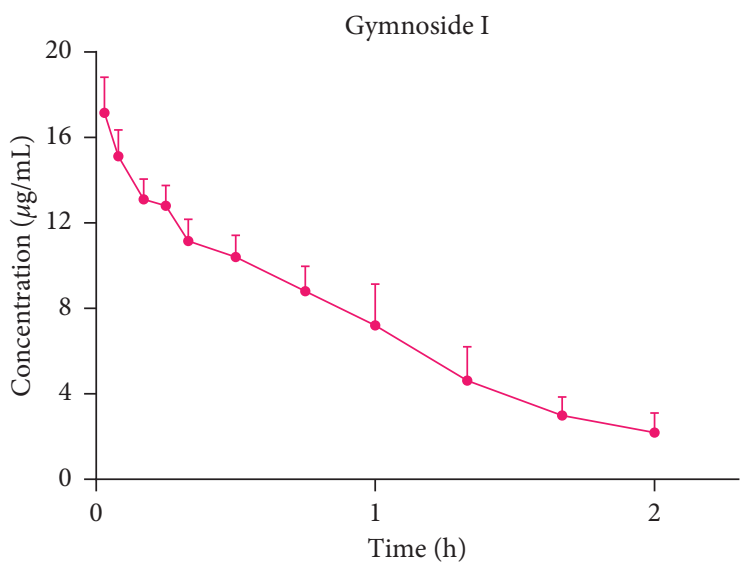

(b)

Figure 4: Continued. 


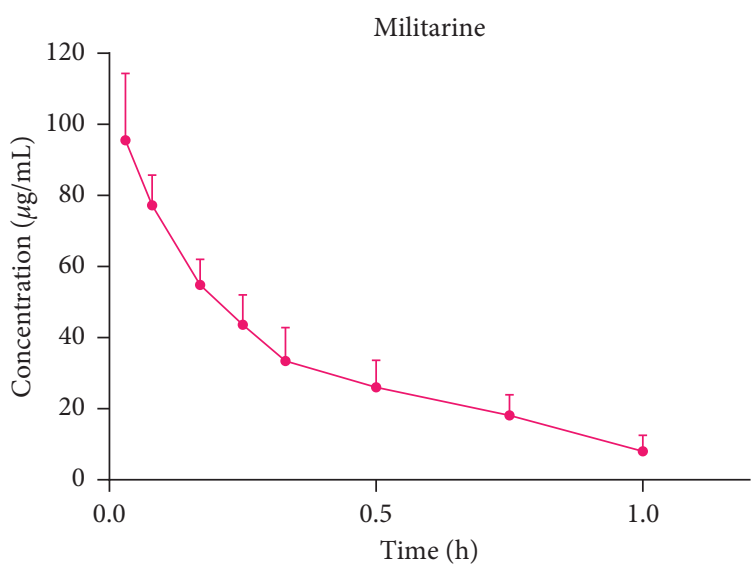

(c)

FIgURE 4: Mean plasma concentration-time curves of $\alpha$-isobutylmalic acid, gymnoside I, and militarine after intravenous administration of B. striata extract to rats $(n=6)$.

TABle 6: Pharmacokinetic parameters of the three analytes after oral and intravenous administration of $B$. striata extract to rats $(n=6)$.

\begin{tabular}{|c|c|c|c|c|c|c|c|}
\hline \multirow{2}{*}{ Parameters } & \multirow{2}{*}{ Unit } & \multicolumn{3}{|c|}{ Intravenous } & \multicolumn{3}{|c|}{ Oral } \\
\hline & & $\alpha$-Isobutylmalic acid & Gymnoside I & Militarine & $\alpha$-Isobutylmalic acid & Gymnoside I & Militarine \\
\hline$T_{\max }$ & $h$ & - & - & - & $6.44 \pm 2.33$ & $1.44 \pm 2.29$ & $0.16 \pm 0.11$ \\
\hline$C_{\max }$ & $\mu \mathrm{g} / \mathrm{mL}$ & - & - & - & $23.18 \pm 5.42$ & $3.06 \pm 4.82$ & $3.30 \pm 3.60$ \\
\hline $\mathrm{AUC}_{0-t}$ & $h * \mu \mathrm{g} / \mathrm{mL}$ & $38.7 \pm 4.72$ & $15.47 \pm 1.63$ & $36.71 \pm 5.66$ & $458.12 \pm 150.74$ & $20.56 \pm 12.05$ & $3.10 \pm 1.16$ \\
\hline $\mathrm{AUC}_{0-\infty}$ & $h * \mu \mathrm{g} / \mathrm{mL}$ & $39.62 \pm 4.26$ & $17.52 \pm 2.66$ & $37.22 \pm 5.99$ & $498.36 \pm 173.09$ & $21.81 \pm 12.04$ & $4.26 \pm 1.93$ \\
\hline $\mathrm{MRT}_{0-t}$ & h & $0.45 \pm 0.08$ & $0.68 \pm 0.07$ & $0.36 \pm 0.06$ & $15.59 \pm 3.63$ & $12.42 \pm 3.73$ & $5.62 \pm 2.45$ \\
\hline $\mathrm{MRT}_{0-\infty}$ & $h$ & $0.51 \pm 0.1$ & $0.93 \pm 0.18$ & $0.39 \pm 0.07$ & $19.69 \pm 6.25$ & $15.98 \pm 5.34$ & $9.31 \pm 2.57$ \\
\hline Bioavailability & $\%$ & - & - & - & $87.4 \%$ & $9.8 \%$ & $0.6 \%$ \\
\hline
\end{tabular}

$\alpha$-isobutylmalic acid and gymnoside I, leading to their higher blood concentrations and longer residence times in vivo. However, this speculation needs further experimental verification. The results of this pharmacokinetic and absolute bioavailability study of B. striata extract after its oral and intravenous administration in rats could provide the basis for the development of strategies for the clinical application of B. striata.

\section{Conclusion}

In this study, the developed LC-MS/MS method for the quantification of $\alpha$-isobutylmalic acid, gymnoside I, and militarine in rat plasma was found to be rapid, sensitive, and reliable. Furthermore, the method was successfully applied to the pharmacokinetic study of B. striata extract after intravenous and intragastric administration, and the absolute bioavailability of $\alpha$-isobutylmalic acid, gymnoside I, and militarine was determined to be $87.45 \%, 9.8 \%$, and $0.6 \%$, respectively. Our results might provide useful information for pharmacokinetic study of other traditional Chinese medicines.

\section{Data Availability}

The data used to support the findings of this study are included within the article.

\section{Conflicts of Interest}

The authors declare that there are no conflicts of interest regarding the publication of this paper.

\section{Authors' Contributions}

Hao Chen and Lin Zheng contributed equally to this work.

\section{Acknowledgments}

This research was supported by the National Natural Science Foundation of China (No. U1812403/81460630); Guizhou Science and Technology Department (Nos. [2019]5660, [2018]4006, and [2017]5601); Guiyang Science and Technology Bureau (No. [2017]30-29); and Guizhou Education Department (No. KY[2018]050).

\section{References}

[1] Editorial Committee of Chinese Pharmacopoeia, Chinese Pharmacopoeia, China Medical Science and Technology Press, Beijing, China, 2015.

[2] L. N. Wang, Y. Z. He, Q. D. Zhao, Y. R. Deng, P. Q. Wu, and Y. J. Zhang, "Phenolic compounds from Bletilla striata," Journal of Asian Natural Products Research, vol. 19, no. 10, pp. 981-986, 2017. 
[3] C. S. Zheng, G. S. Feng, and H. M. Liang, "Bletilla striata as a vascular embolizing agent in interventional treatment of primary hepatic carcinoma," Chinese Medical Journal, vol. 111, no. 12, pp. 1060-1063, 1998.

[4] H. Y. Hung and T. S. Wu, "Recent progress on the traditional Chinese medicines that regulate the blood," Journal of Food and Drug Analysis, vol. 24, no. 2, pp. 221-238, 2016.

[5] X. He, J. Fang, X. Wang et al., "Bletilla striata: medicinal uses, phytochemistry and pharmacological activities," Journal of Ethnopharmacology, vol. 195, pp. 20-38, 2017.

[6] S. Shi, Z. Huang, Y. Luo, and J. N. Chen, "Bletilla striata polysaccharide for the treatment of ulcerative colitis in mice," Journal of China Pharmaceutical University, vol. 43, no. 6, pp. 535-540, 2012.

[7] W. Yu, J. Liu, L. Qiu, Y. Wang, and C. Wang, "Two natural glucomannan polymers, from Konjac and Bletilla, as bioactive materials for pharmaceutical applications," Biotechnology Letters, vol. 37, no. 1, pp. 1-8, 2015.

[8] S. Takagi, M. Yamaki, and K. Inoue, "Antimicrobial agents from Bletilla striata," Phytochemistry, vol. 22, no. 4, pp. 1011-1015, 1983.

[9] M. Yamaki, L. Bai, K. Inoue, and S. Takagi, "Biphenanthrenes from bletilla striata," Phytochemistry, vol. 28, no. 12, pp. 3503-3505, 1989.

[10] J. E. Park, K. W. Woo, U. C. Sang, J. H. Lee, and R. L. Kang, "Two new cytotoxic spirostane-steroidal saponins from the roots of bletilla striata," Helvetica Chimica Acta, vol. 97, no. 1, pp. 56-63, 2014.

[11] J. Qian, D. Vossoughi, D. Woitaschek et al., "Combined transarterial chemoembolization and arterial administration of Bletilla striata in treatment of liver tumor in rats," World Journal of Gastroenterology, vol. 9, no. 12, pp. 2676-2680, 2003.

[12] A. Sun, J. Liu, S. Pang, J. Lin, and R. Xu, "Two novel phenanthraquinones with anti-cancer activity isolated from Bletilla striata," Bioorganic \& Medicinal Chemistry Letters, vol. 26, no. 9, pp. 2375-2379, 2016.

[13] L. X. Wang, G. X. Han, Y. Shu, W. Y. Liu, and W. D. Zhang, "Studies on chemical constituents of bletilla striata (Thunb) Reichb.f.," China Journal of Chinese Materia Medica, vol. 26, no. 10, pp. 691-692, 2001.

[14] X. Yang, C. Tang, P. Zhao, G. Shu, and Z. Mei, “Antimicrobial constituents from the tubers of Bletilla ochracea," Planta Medica, vol. 78, no. 6, pp. 606-610, 2012.

[15] L. Yang, C. Peng, C. W. Meng et al., "A new macrolide and six cycloartane triterpenoids from the tubers of Bletilla striata," Biochemical Systematics \& Ecology, vol. 57, no. 57, pp. 238241, 2014.

[16] F. F. Zhao, X. Yang, X. U. Dan et al., "Hemostatic effect and mechanism of a non-polysaccharide fraction of Bletilla striata," Chinese Pharmacological Bulletin, vol. 32, no. 8, pp. 1121-1126, 2016.

[17] F. F. Zhao, L. C. Lin, X. Yang et al., "Effects of a non-polysaccharide fraction of Bletilla striata on platelet activation and hemorheology in rats," Chinese Traditional Patent Medicine, vol. 39, no. 2, pp. 244-249, 2017.

[18] Z. W. Ning, L. X. Zhai, J. Peng et al., "Simultaneous UPLCTQ-MS/MS determination of six active components in rat plasma: application in the pharmacokinetic study of leaves," Chinese Medicine, vol. 14, no. 1, p. 28, 2019.

[19] C. Y. Mei, W. Y. Xiang, W. Yang, Y. Huang, Y. L. Wang, and A. M. Wang, "Simultaneous determination of six components in Bletilla striata by UPLC-MS/MS," Natural Product Research and Development, vol. 28, no. 8, pp. 1233-1237, 2016.
[20] H. Chen, C. Q. Wang, T. Xia et al., "Study on the absorbable components and metabolism of Bletilla striata effective parts in the intestine based on rat intestinal perfusion model," Natural Product Research and Development, vol. 31, no. 5, pp. 772-778, 2019.

[21] C. Q. Wang, T. Xia, and H. Chen, "Metabolism of militarine component of the effective fractions of Bletilla striata in zebrafish," Chinese Jounral of New Drugs, vol. 28, no. 4, pp. 467-472, 2019.

[22] A. M. Wang, Y. Yan, B. Lan, S. G. Liao, Y. L. Wang, and Y. J. Li, "Simultaneous detemination of nine chemical markers of Bletillae Rhizoma by ultra performance liquid chromatography," China Journal of Chinese Materia Medica, vol. 39, no. 11, pp. 2051-2055, 2014.

[23] X. He, A. Wang, Y. J. Li, Y. Wang, and S. Zhou, "Determination of militarine Rhizoma bletillae by HPLC," China Journal Chinese Materia Medica, vol. 34, no. 16, pp. 20762078, 2009.

[24] X. X. Xu, G. T. Xu, X. P. Li, X. Zhong, H. W. Jian, and Z. Xu, "Effect and mechanism of militarine in relaxing isolated thoracic aorta rings in rats," Chinese Archives of Traditional Chinese Medicine, vol. 33, no. 3, pp. 617-620, 2015.

[25] Y. Wang, X. Y. Zhao, X. Y. Li, S. Li, and J. J. Zhang, "Militarine alleviates white matter damage and cognitive impairment in rats with chronic cerebral hypoperfusion," Acta Pharmaceutica Sinica, vol. 51, no. 5, pp. 738-742, 2016.

[26] Y. Chang, X. Tao, W. Changquan et al., "Using the UPLC-ESIQ-TOF-MSE method and intestinal bacteria for metabolite identification in the nonpolysaccharide fraction from Bletilla striata," Biomedical chromatography, 2019.

[27] H. Y. Sun, L. Zheng, Z. P. Gong et al., "A validated HPLC-MS/ MS method for simultaneous determination of militarine and its three metabolites in rat plasma: application to a pharmacokinetic study," Evidence-Based Complementary and Alternative Medicine, vol. 2019, Article ID 2371784, 9 pages, 2019. 


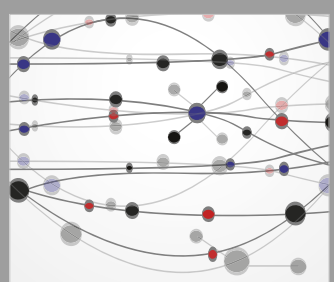

The Scientific World Journal
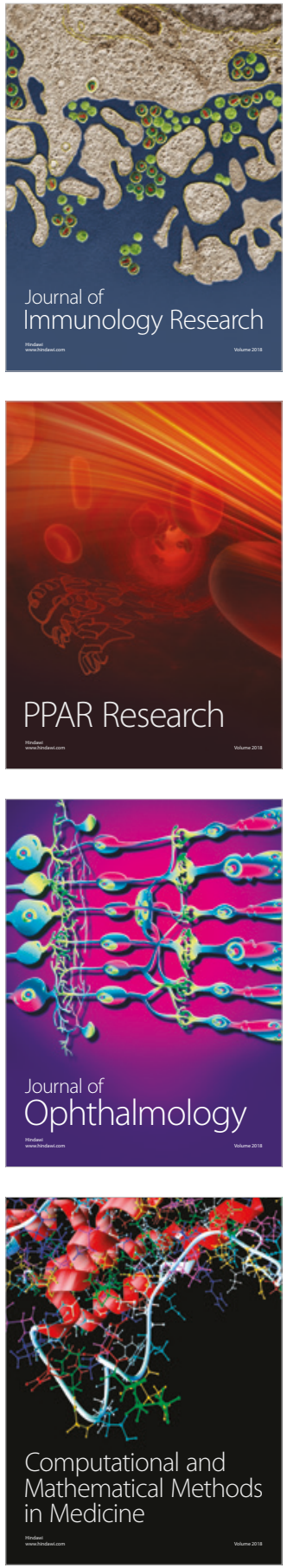

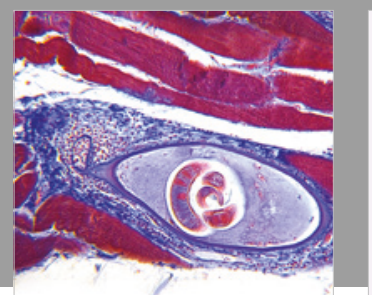

Gastroenterology Research and Practice

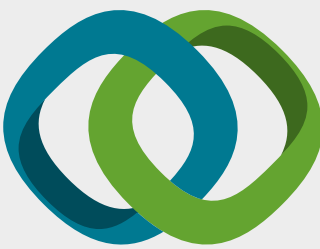

\section{Hindawi}

Submit your manuscripts at

www.hindawi.com
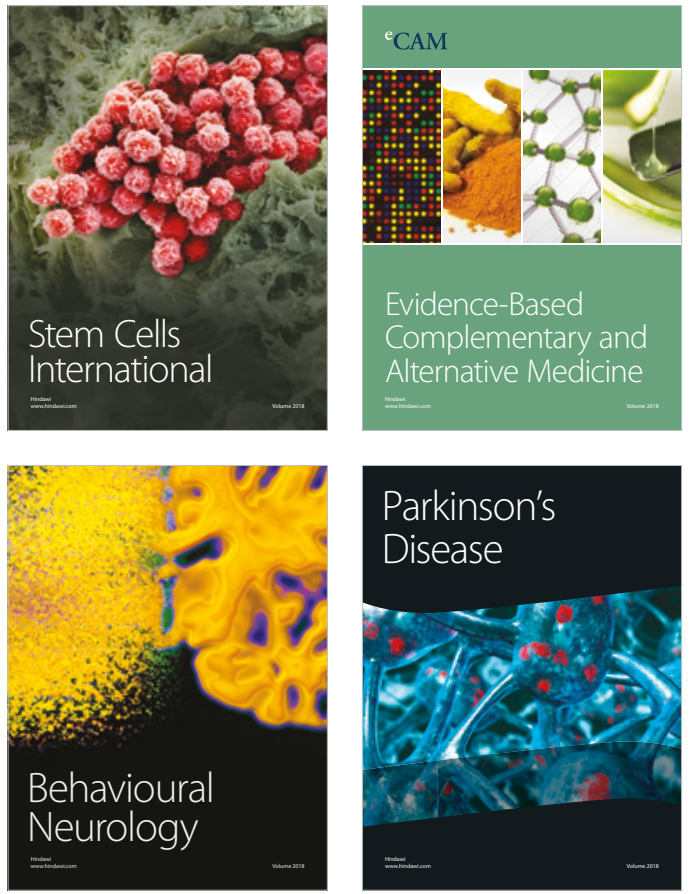

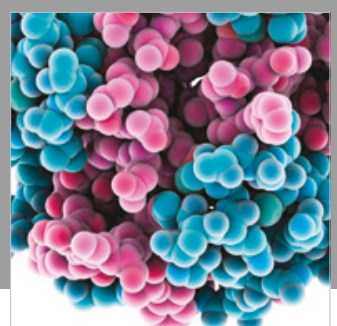

ournal of

Diabetes Research

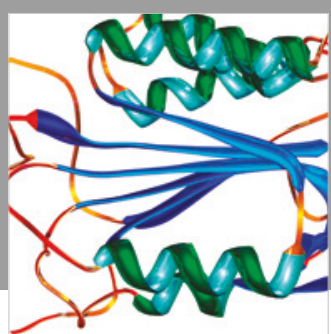

Disease Markers
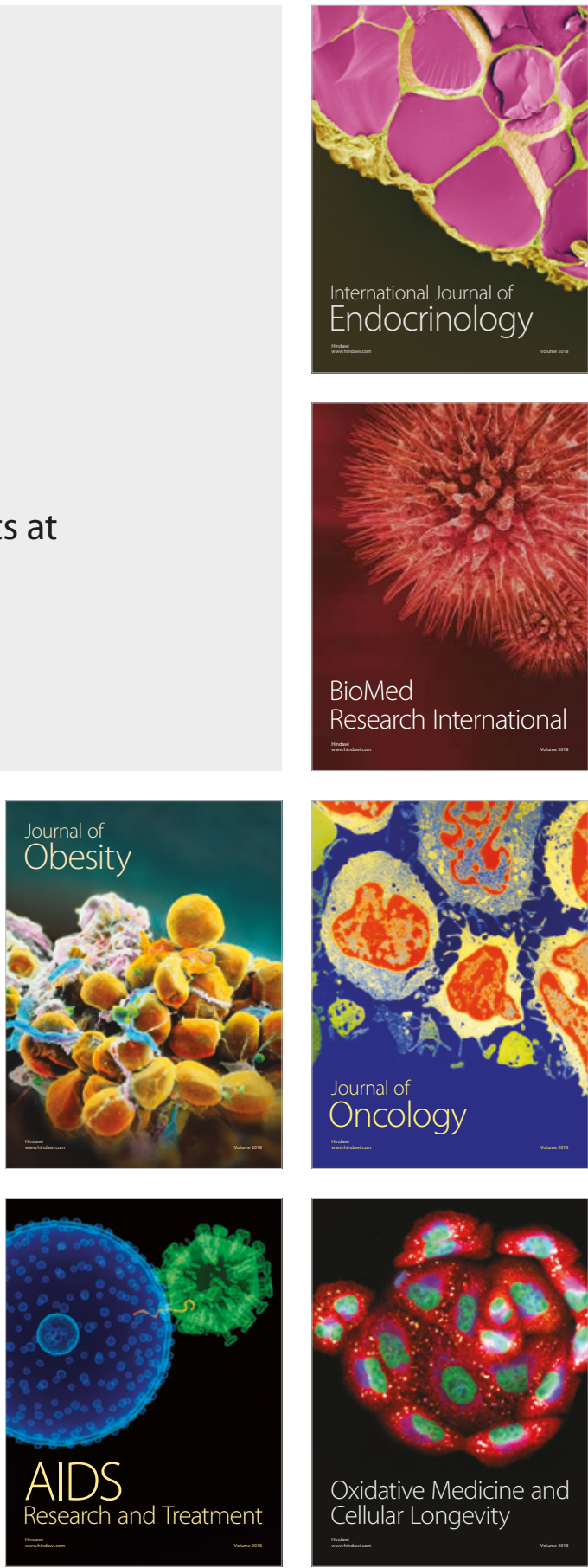